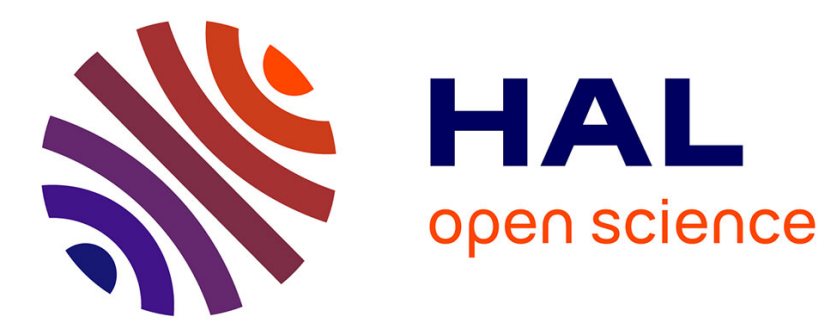

\title{
On Descriptional Propositions in Ibn Sīnā: Elements for a Logical Analysis
}

Shahid Rahman, Mohammad Saleh Zarepour

\section{To cite this version:}

Shahid Rahman, Mohammad Saleh Zarepour. On Descriptional Propositions in Ibn Sīnā: Elements for a Logical Analysis. 2019. hal-02381959

\section{HAL Id: hal-02381959 \\ https://hal.univ-lille.fr/hal-02381959}

Preprint submitted on 26 Nov 2019

HAL is a multi-disciplinary open access archive for the deposit and dissemination of scientific research documents, whether they are published or not. The documents may come from teaching and research institutions in France or abroad, or from public or private research centers.
L'archive ouverte pluridisciplinaire HAL, est destinée au dépôt et à la diffusion de documents scientifiques de niveau recherche, publiés ou non, émanant des établissements d'enseignement et de recherche français ou étrangers, des laboratoires publics ou privés. 


\section{On Descriptional Propositions in Ibn Sīnā: Elements for a Logical Analysis}

\author{
Shahid Rahman
}

\author{
Mohammad Saleh Zarepour
}

\section{Introduction}

In his discussions of the various readings of modal propositions, Ibn Sīnā's focus is mostly on a distinction which was later labelled the distinction between descriptional (wașfí) and substantial ( $\underline{d} \bar{a} t \bar{l})$ readings of a modal proposition. ${ }^{1}$ Given that for Ibn Sīnā all categorical propositions are either implicitly or explicitly modal, the substantialdescriptional distinction is in some sense applicable to the readings of all categorical propositions. $^{2}$ This distinction is based on how (i.e., under which conditions) the predicate of a categorical proposition is true of its subject. According to the substantial reading, the predicate is true of the subject (perhaps with a certain alethic or temporal modality) as long as the substance of the subject exists. On the other hand, according to the descriptional reading, the predicate is true of the subject (again, perhaps with a certain modality) as long as the substance of the subject is truly described by the subject. To be clearer, consider the following proposition:

(1) Every $S$ is $P .^{3}$

The difference between the substantial and descriptional readings of (1) can be articulated as follows:

Substantial Reading of (1): Every $S$, as long as it exists, is $P$.

\footnotetext{
${ }^{1}$ Hasnwai and Hodges (2017, p. 61) have correctly pointed out that 'substantial' is not Ibn Sīnā's own term. Indeed, as Strobino and Thom (2017, p. 345) have mentioned, it is only in the later stage of the tradition of Arabic logic that the terminology of 'substantial' and 'descriptional' became mainstream. Some of the other names which have been employed to refer to the distinction under discussion will be mentioned later in the chapter.

${ }^{2}$ Street (2002, sec. 1.1) and Strobino and Thom (2017, sec. 14.2.1) emphasize that for Ibn Sīnā all propositions have either temporal or alethic modality. Absolute propositions are implicitly modal and all other propositions are explicitly modal. Lagerlund (2009, p. 233) highlights that even the absolute propositions can be taken to be descriptional.

${ }^{3}$ Strictly speaking, there is an important difference between a sentence and the proposition expressed by it. Accordingly, it is a sentence (rather than a proposition) which can be read in different ways. So what a substantial (respectively, descriptional) reading of a sentence expresses is a substantial (respectively, descriptional) proposition. Nonetheless, such a clear difference between sentence and proposition cannot be detected either in Ibn Sīnā's own discussion of the substantial-descriptional distinction or in the secondary literature on this issue. So to remain more focused on the main points we would like to make-and of course for the sake of simplicity-we do not make the sentence-proposition distinction bold.
} 
Descriptional Reading of (1): Every $S$, as long as it is $S$, is $P$.

It is in principle possible that a proposition is true on one of these readings and false on the other. It is only the context which determines how a proposition must be read to be true. ${ }^{4}$ To give an example, consider the following proposition:

(2) Every bachelor is unmarried.

The substantial and descriptional readings of (2) are respectively as follows:

(3) Every bachelor, as long as he exists, is unmarried.

(4) Every bachelor, as long as he is bachelor, is unmarried.

These two propositions have different truth values. Contrary to (3)-which is false-(4) is true. This is because a bachelor is unmarried only insofar as he is described as a bachelor. So (4) is true. By contrast, it is in principle possible for a person who is a bachelor in some period(s) of time to be married in some other period(s) of time; this is so at least if we assume that 'as long as' has a temporal meaning. In other words, it is not necessary for such a person to be always unmarried. The mere existence of the substance of this person does not guarantee his being unmarried. Thus (3) is false. There are, however, other propositions that are true on the substantial reading. For example, consider the following proposition:

(5) Every human is animal.

The predicate Animal is true of every human as long as s/he exists. Put otherwise, what makes it true to say that every human is animal is the mere existence of human substances. This means that not only the descriptional but also the substantial reading of (5) is true. ${ }^{5}$ Indeed, since every human exists if and only if s/he is human, the substantial and descriptional readings of (5) express one and the same fact.

As Ibn Sīna himself insists, he is the first logician to have focused on the above distinction and pondered on its fruitfulness for removing some difficulties with Aristotle's syllogistic. ${ }^{6}$ Since the distinction plays a crucial role in Ibn Sīnā's syllogistic, it is discussed in several places in his logical oeuvre. ${ }^{7}$ Moreover, the distinction was subject to continually

${ }^{4}$ See Hodges and Johnston (2017, p. 1057).

5 These examples are adopted from El-Rouayheb (2019, p. 24).

${ }^{6}$ See al-Qiyās (1964, Chapter III.1, p. 126) in which Ibn Sīnā complains that previous philosophers have not paid enough attention to this distinction.

${ }^{7}$ A famous passage in which Ibn Sinnā discusses this distinction can be found in the logic part of al-Išărāt (1983, Chapter 4.2, pp. 264-266). For translations of this passage see Street (2005, pp. 259-260) and Ibn Sīnā (1984, Chapter 4.2, p. 92). In the logic part of al-Nağăt (1985, pp. 34-37)-whose translation can be found in Ahmed (2011, sec. 48)-Ibn Sīnā proposes six different readings of necessary propositions. The second and the third readings include respectively substantial and descriptional necessities. This distinction is discussed also in al-Qiyās (1964) and Manțiq al-Mašriqìyin (1910). Translations of some relevant passages from these two works are provided by Hodges and Johnston (2017, Appendix A.2). They discuss a distinction between darūrī and lāzim propositions in passages from Manțiq al-Mašriqìyin that is tantamount to the distinction between substantial and descriptional readings of propositions. 
heated discussions in Arabic logic after Ibn Sīnā. For instance, the distinction was accepted by Rāzì and Khūnağì, on the one hand, and was seen as redundant by Ibn Rushd. ${ }^{8}$ The substantial sense of propositions corresponds to what is called the 'divided' sense of propositions in the Latin tradition. However, although the descriptional sense of propositions is plays an important role in Arabic syllogistic, it has no widely discussed counterpart in the Latin tradition. ${ }^{9}$ These observations strongly suggest that a comprehensive picture of Arabic syllogistic from Ibn Sīnā onwards cannot be achieved unless we have a clear logical analysis of the aforementioned distinction. An effective and popular strategy for providing such an analysis is to look at the different readings of a proposition through the lens of modern formal logic. Therefore, it is important to find out which formal language has the best capacity to capture various aspects of this distinction and the insights behind it. In the literature, several attempts have been made to formalize the different readings of propositions in the languages of classical predicate or temporal logics. ${ }^{10}$ In this chapter, we put forward an alternative based on Martin-Löf's constructive type theory (CTT). ${ }^{11}$ Compared to its rivals, our analysis is more faithful to the grammatical subject-predicate structure of propositions and can better reflect the morphological features of the verbs (and descriptions) that extend time to intervals (or spans of times). It is worth noting that our focus will mostly be on the analysis of the descriptional reading of propositions (which can also be called 'the descriptional propositions' for the sake of brevity).

\section{On What and How}

The distinction between substantial and descriptional propositions seems to be related to Joseph Almog's famous distinction between what and how a thing is. ${ }^{12}$ More precisely, it is relevant to how the subject term of a categorical proposition is true of its objects in the two different readings we introduced above. The expression ' $a$ is $S$ ' can in principle encode two basic forms of predication. The expression encodes what $a$ is, if $S$ represents an essential feature of $a$. For instance, if $S$ is a genus of $a$ or a category to which $a$ belongs, then ' $a$ is $S$ ' encodes (at least partially) what $a$ is. ${ }^{13}$ On the other hand, the

\footnotetext{
8 See El-Rouayheb (2017, pp. 72 \& 81).

${ }^{9}$ See Street (2002, p. 133).

10 See, among others, Rescher and vander Nat (1974), Hodges and Johnston , and Chatti (2019a, 2019b).

11 See Martin-Löf (1984). In what follows, a basic familiarity with CTT is assumed. All the background requirements can be found in Rahman et al. (2018, Chapter 2).

12 See Almog $(1991,1996)$.

13 As pointed out by Ranta (1994, p. 55), "the most serious criticism against the type-theoretical analysis of everyday language comes from intuitionistic thinking" (i.e., from the very same framework within which CTT is developed). The concern is that although intuitionistic logic is an appropriate tool for mathematical reasoning, its application outside mathematics is inappropriate. This is mainly because, by contrast with mathematical reasoning in which objects are almost always fully presented, everyday reasoning is usually based on an incomplete presentation of objects. For example, although a natural number can be fully
} 
expression ' $a$ is $S$ ' encodes how $a$ is, if $S$ represents an accidental feature of $a$. For instance, if $S$ is a description which can be sometimes but not always true of $a$, then ' $a$ is $S$ ' encodes (again, at least partially) how $a$ is.

Returning to the distinction between substantial and descriptional propositions, it seems that the subject term of a true substantial proposition establishes what its objects are. By contrast, the subject term of a true descriptional proposition establishes how its objects are. For example, ' $a$ is human' expresses what $a$ is. But ' $a$ is bachelor' expresses how $a$ is. ${ }^{14}$ So a reasonable expectation of an accurate analysis of substantial and descriptional propositions is that it must capture the difference between what and how things are. This shows that classical logic cannot be an eligible candidate for the frameworks in which such an analysis is supposed to be provided. This is because those different forms of predication cannot be distinguished in classical logic, where there is only one way to analyse the expression ' $a$ is $S$ ', namely as the propositional function $S(a)$. It is, therefore, an advantage of CTT over classical logic that the language of the former is sensitive to the difference between these two kinds of predication.

Suppose that ' $a$ is $A$ ' expresses what $a$ is. This can be captured in the framework of CTT as $a$ 's being a member of the category (or domain or type) $A$. The latter notion can be represented in the language of CTT as follows:

$$
a: A
$$

In this expression ':' can be read as 'is' (in the sense of expressing the what) or, equivalently, as 'belongs to'. Moreover, suppose that ' $a$ is $B$ ' expresses how $a$ is. In other words, the expression describes $a$ as having the property $B$ and this expression constitutes a proposition. This can be captured in the language of CTT as follows:

$B(a): p r o p$

presented by its canonical expression, giving a full presentation of a continent seems to be extremely difficult, if not impossible. Stated differently, the presentations of continents (like as many other things) in the natural language is usually incomplete in the sense that they are usually referred to by expressions which only partially determine what a continent is. There seems to be no canonical expression of the non-mathematical objects like continents, humans, trees, etc. One possible way to deal with this concern, as Ranta (1994, pp. 5556) suggests, is "to study delimited models of language use, 'language games'. Such a 'game' shows, in an isolated form, some particular aspect of the use of language, without any pretention to covering all aspects." For example, a term like 'human', depending on the context, can be partially modelled by the set of canonical names of the people who are referred to by the term 'human' in that specific context. Accordingly, a set like \{John, Mary, Jones, Madeline\} can be considered as the interpretation of the term 'human' in a certain context. The elements of such a set are fully represented by the canonical names 'John', 'Mary', etc. Although we are still far from the full presentation of humans in flesh and blood, we have a model which enables us to formalize certain fragments of language in which talking about humans is nothing but talking about those four persons. By developing such models, we can formalize larger fragments of language. An alternative dialogical approach for dealing with this concern is put forward by Rahman et al. (2018, sec. 10.4). This dialogical alternative is inspired by Martin-Löf (2014).

${ }^{14}$ This picture needs to be refined. As we will shortly see, even in the descriptional reading the whatness of the objects of the subject term is mentioned, albeit only implicitly. 
In this expression ' $p r o p$ ' represents the category of propositions. Accordingly, that $a$ is an object of the type $A$ which bears the description $B$ can be expressed by combining the two previous expressions as follows:

$B(a)$ : prop, given $a: A$.

More generally, $B(x)$ constitutes a proposition when an $x$ that is of the category $A$, bear the description $B$. Formally,

$B(x): \operatorname{prop}(x: A)$

In fact, this expresses the well-formedness of the predicate $B(x) .{ }^{15}$ It determines the domain upon which the predicate is defined. More explicitly, it clarifies that $B$ is predicated upon the objects which belong to the set $A$. In general, the CTT formation rules for predicates are in accordance with Plato's observation that how something is cannot be asserted without presupposing what that thing is. ${ }^{16}$ Once the well-formedness of a predicate has been established, we can produce formal structures expressing that the predicate is true of some objects. For example, that $B$ is true of $a$, which is an arbitrary but fixed element of $A$, can be expressed by:

$B(a)$

Similarly, that some or all of the elements of $A$ are $B$ can be expressed, respectively, by the following expressions:

$(\exists x: A) B(x)$

$(\forall x: A) B(x)$

In all of the latter three expressions the formation rule $B(x): \operatorname{prop}(x: A)$ is presupposed. ${ }^{17}$

By employing this machinery, the grammatical structure of categorical propositions can comprehensively be reflected in the language of CTT and this can be counted as a significant advantage of CTT over classical logic. Consider the proposition 'some students are good'. An oversimplified analysis of this proposition within the classical logic with unrestricted quantification would be as follows:

$(\exists x)[\operatorname{Student}(x) \wedge \operatorname{Good}(\mathrm{x})]$

15 In CTT, the well-formation is not only syntactic but also semantic. Consider, for example, the predicate Hungry. The well-formedness of this predicate can be expressed by 'Hungry(x) : prop ( $x$ : Animal)', which reveals not only the correct syntactical use of that predicate but also the semantic domain of the objects of which that predicate can be true.

${ }^{16}$ In their thorough and meticulous discussion of Plato's Cratylus, Lorenz and Mittelstrass (1967) highlight

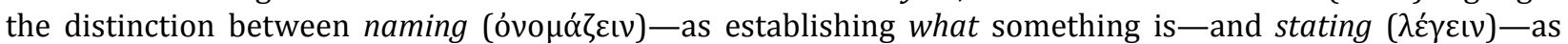
establishing how something is. They $(1967$, p. 6$)$ point out that " $[t]$ he subject has to be effectively determined, i.e., it must be a thing correctly named, before one is going to state something about it"

17 In CTT, the judgment that the proposition $B(a)$ is true is usually represented by ' $B(a)$ true'. But as long as we are considering a proposition itself (without making any judgment that it is true) we do not really need to add 'true'. 
By contrast, in the language of CTT, 'some students are good' could be formalized by this notation:

\section{$(\exists x:$ Student $) \operatorname{Good}(x)$}

The latter translation restricts Good to the grammatical subject of the proposition i.e., Student. It singles out the set of those students that are good insofar as they are students. Quite the contrary, the former translation does not distinguish the subject and predicate. It coarsely refers to persons who are both good and student, no matter whether or not that those persons are good at being a student or at something else. To discuss one of Ibn Sīnā's own examples, consider the following propositions:

(6) Imra'a al-Qays is good.

(7) Imra'a al-Qays is poet.

(8) Imra'a al-Qays is a good poet.

Ibn Sīnā argues that (8) cannot be concluded from the conjunction of (6) and (7).18 For him, such an argument is fallacious. But if we translate these propositions in the language of classical predicate logic, we cannot see why this argument is fallacious. Suppose that ' $a$ ' refers to Imra'a al-Qays, and 'Poet' and 'Good' represents, respectively, being a poet and being good. An oversimplified translation of (6)-(8) in the framework of classical logic (with unrestricted domain of quantification) yields:

$$
\begin{aligned}
& (6-C L) \operatorname{Good}(a) \\
& (7-C L) \operatorname{Poet}(a) \\
& (8-C L) \operatorname{Poet}(a) \wedge \operatorname{Good}(a)
\end{aligned}
$$

In such a framework, concluding (8-CL) from (6-CL) and (7-CL) is unproblematic. But this is an undesirable result for Ibn Sinā. This shows that such a framework is not suitable for formalizing Ibn Sinā's logic. By contrast, in CTT the propositions (6)-(8) would be translated as follows:

(6-CTT) Good (a) : prop, given $a:$ Human. ${ }^{19}$

(7-CTT) Poet(a) : prop, given $a$ : Human.

(8-CTT) Good(a) : prop, given $a$ : Poet.

(8-CTT) cannot be concluded from (6-CTT) and (7-CTT); and this is exactly what Ibn Sīnā expects.

\section{Substantial and Descriptional Propositions}

\footnotetext{
18 Ibn Sīnā proposes this example in the logic part of al-Ǐ̌ārāt (1983, Chapter 10.1, pp. 501-502). We are grateful to Alexander Lamprakis for drawing our attention to this example.

19 That Imra'a al-Qays belongs to the category Human is not explicitly mentioned in (6) and (7). But it is necessary be added to the picture. See the next section for more details on this issue.
} 
Consider the following proposition:

(9) Every moving is changing. ${ }^{20}$

The substantial and descriptional readings of (9) can be stated respectively as follows:

(10) Every moving, as long as it exists, is changing.

(11) Every moving, as long as it is moving, is changing.

It is not the case that every moving object, as long as its essence exists, is changing. Rather, it is changing as long as its essence can be described as moving. A moving object can in principle stop moving at some time without ceasing to exist. So (9) is true only if it is read in the descriptional sense as (11), rather than in the substantial sense as (10). To see how the difference between (10) and (11) can be mirrored in their formal constructions in the language of CTT, a deeper investigation about the subject and predicate of these propositions needs to be carried out.

At first sight the subject of (9) is Moving and the predicate is Changing. However, Moving is a description whose bearer is concealed (mudmar). Thus it is legitimate to ask what the category of moving objects is. Put otherwise, what is the type of the things which are supposed in (9) to be Moving?21 (9) itself does not determine whether moving things are supposed to be, for example, humans, animals, or bodies (ağsām) in general. This can be established only by the context in which (9) is stated. But in any case it is undoubtable that moving things must be considered to be of a specific category, even if this category is not explicitly mentioned. To preserve the generality of our analysis we can assume that this category is $O$. It means that (9) expresses a fact about those objects of the type $O$ which are moving. Depending on the context, $O$ can be replaced with the categories like Human, Animal, or, more generally, Body.

According to this understanding, every element which lies in the scope of the universal quantifier of (9) has two different aspects. One aspect reveals what it is (i.e., it belongs to $O$ ) and the other reveals how it is (i.e., it is moving). In other word, if $z$ is an element in the scope of the universal quantifier of (9)-i.e., if $z$ is one of those objects that are moving-it can be represented as having the canonical form $\langle x, b(x)>$ in which $x$ is of the type $O$ and $b(x)$ is a method evidencing that $x$ can be described as being Moving. $b(x)$ can be seen as a truth-maker or a proof for the proposition that $x$ is moving. ${ }^{22}$ The difference between the substantial and descriptional readings of (6) is rooted in how these two different components are combined with each other and in the roles each of them plays in

\footnotetext{
${ }^{20}$ The example is borrowed from the logic part of al-Išārāt (1983, Chapter 4.2, p. 265).

${ }^{21}$ On how and why the bearer of the subject of descriptional propositions is concealed see Schöck (2008, pp. 350-351).

${ }^{22}$ A truth-maker is in fact a rudimentary form of what is called proof-object in CTT. See Ranta (1994, p. 54). However, in the context of this chapter, we assume 'truth-maker' and 'proof-object' to be synonymous terms. It is also worth mentioning that in the CTT-framework one and the same true proposition has according to the rule more than one object which makes it true.
} 
the predication. The descriptional reading of (9)-i.e., (11)—can be formalized in the language of CTT as follows:

(11-CTT) $\{\forall z:(\exists x: O)$ Moving $(x)\}$ Changing $(l e f t(z))$

\section{Subject \\ Predicate \\ $(\exists x: O) \operatorname{Moving}(x)$ \\ Changing (left $(z))$}

In this translation, left can be interpreted as a projection function which extracts the left-side element of every $z$. Similarly, right can be defined as the projection function which extracts the right-side element of every $z$. So if $z$ is considered to be a compositum of the form $<x, b(x)>$ in which $x$ is of the type $O$ and $b(x)$ is a method evidencing that $x$ can be described as moving, then $\operatorname{left}(z)=\operatorname{left}(<x, b(x)>)=x: O$ and $\operatorname{right}(z)=\operatorname{right}(<x, b(x)>)=b(x)$ : Moving $(x)(x: O)$. The above construction can be seen as involving an anaphora whose head is Moving- $O$ (i.e., it is an object of the type $O$ that is Moving). The tail of the anaphora is constituted by the projection function left $(z)$ which picks out those objects of the type $O$ that are described as moving in the grammatical subject.

Philosophically speaking, in the descriptional reading of (9), the two different aspects of the subject (i.e., the one which reveals what it is and the one which reveals how it is) are merged into a compound unity, so that each constituent carries the information about the other. Now it is this compound unity upon which Changing is predicated. More precisely, the subject is assumed to have a whatness (i.e., its belonging to $O$ which can also be seen as the substantial component of the subject) and a howness (i.e., its being moving which can also be seen as the descriptional component of the subject). In the descriptional reading these two aspects are combined with each other to make a new compound whatness (i.e., Moving-O) upon which another howness (i.e., Changing) is predicated. Such a compound whatness plays no role in the substantial reading of (9). In (10), the objects upon which Changing is going to be predicated are still selected by the description Moving from the domain of the objects of type $O$. Nonetheless, the truth of such a substantial predication is not supposed to be dependent on whether or not those objects preserve the description Moving. In general, in the substantial predication the objects of predication are selected by a description but the truth of the predication does not depend on whether or not those objects preserve the description. By contrast, in the descriptional reading not only are the objects of predication selected by the description but also the predication is true only as long as those objects preserve the description. Given these observations, our proposal for the translation of the substantial reading of (9)-i.e., (10) - goes as follows:

(10-CTT) $\{\forall z:(\exists x: O \mid$ Moving $(x))\}$ Changing(first $(z))$

\section{Subject}

$(\exists x: O \mid$ Moving $(x))$

\section{Predicate}

Changing $($ first $(z))$ 
Here the description Moving is characterizing the domain of the objects of the type $O$ upon which Changing is predicated. Nonetheless, the description is not a component of the unified whatness upon which Changing is predicated. The subject is not considered as a compound entity of which the description Moving is an irremovable component. Moreover, to highlight the distinction between the substantial and descriptional reading, instead of left and right, here we use the projection functions first and second. The main difference between these two couples of the projection functions is that when one of the functions of the former couple extracts an element of the pair $\langle x, b(x)>$, the selected element carries some piece of information about the other element. By contrast, what is selected by one of the functions of the latter couple does not contain any piece of information about the the other element. So first $(z)$ selects one instantiation of $O$ and forgets about the second component of $z .23$

To generalize our formalizations, reconsider the proposition (1)—i.e., 'every $S$ is $P^{\prime}$ and suppose that $S$ is a description whose bearers are of the type $D$. The descriptional and substantial reading of this proposition can be formalized as follows:

Substantial Reading of (1): $\{\forall z:(x: D \mid S(x))\} P($ first $(z))$

Descriptional Reading of (1): $\{\forall z:(\exists x: D) S(x)\} P(\operatorname{left}(z))$

Now we can easily see the advantage of this analysis over one of its rivals which is proposed in the framework of classical predicate logic. Saula Chatti formalizes the descriptional reading of (1) as follows:

$$
(\forall x)[S(x) \supset(S(x) \supset P(x))] \wedge(\exists \mathrm{x}) \mathrm{S}(\mathrm{x})
$$

As she herself pointed out, the above proposition is equivalent to:

$$
(\forall x)(S(x) \supset P(x)) \wedge(\exists \mathrm{x}) \mathrm{S}(\mathrm{x})
$$

But this is exactly what classical predicate logic proposes for the formalization of all $A$-form absolute propositions. So it cannot reflect how the descriptional reading of a proposition differs from the other possible readings. ${ }^{24}$

These formalizations enable us to see better how some seemingly contradictory propositions, like the two below, can be both true at the same time:

(12) Every sitting, as long as it exists, can walk.

(13) Every sitting, as long as it is sitting, cannot walk.

In (13) the subject must be taken as a compound entity to which the predicate Cannot-walk applies. Here the projection function left selects only those dogs that are sitting. In (12), the

${ }^{23}$ To put it in more technical language, if in the proposition 'every $B$, as long as it exists, is $C$ ', the bearers of the description $B$ are of the type $A$, then first $(z): A$ must be understood as what Sundholm $(1989$, p. 10) calls ' $A$ injection'. The evaluation of an A-injections on $z$ is the same member $z$ of $A$; e.g., first $(z)=z: A$.

${ }^{24}$ See Chatti (2019b, pp. 113-114). Since Ibn Sīnā considers existential import for $A$-form propositions, Chatti emphasizes that the above formulas must include the conjunct ' $(\exists x) S(x)^{\prime}$. 
function first takes the subject in its substantial sense. This means that although the subject is analysed into Dog and Sitting, when first selects a dog, its selection does not carry information on whether or not the dog is sitting. So the formal translations of (12) and (13) go respectively as follows:

(12-CTT) $\{\forall z(x: \operatorname{Dog} \mid \operatorname{Sitting}(x))\}$ Can-walk(first(z))

(13-CTT) $\{\forall z:(\exists x:$ Dog) Sitting $(x)\}$ Cannot-walk(left $(z))$

So far so good. But our conception of the roles Ibn Sīnā considers for the substantialdescriptional distinction in different contexts will not be comprehensive until we understand how the time-parameter and the existence predicate can be added to the picture.

\section{Time Parameters}

Time parameters add more complexities to the structure of descriptional propositions. But, fortunately, CTT has the capacity to handle them. Reconsider the following descriptional proposition propositions:

(11) Every moving, as long as it is moving, is changing.

Which is equivalent to:

(14) Every moving is changing while it is moving.

Now if we add the time parameter, (14) can be read as follows:

(15) Every moving is changing all the time it is moving.

This proposition is usually rendered as an equivalent of the following proposition:

(16) Every (sometime-)moving is changing all the time it is moving. ${ }^{25}$

Accordingly, (16) is usually formalized as follows:

$$
\begin{aligned}
& (16-\mathrm{CL}) \quad(\forall x)[(\exists \mathrm{t}) \text { Moving }(t, x) \quad \supset \quad(\forall \mathrm{t})(\text { Moving }(t, x) \quad \supset \quad \text { Changing }(t, x))] \wedge \\
& (\exists t)(\exists x) \text { Moving }(t, x)
\end{aligned}
$$

In this analysis ' $x$ ' and ' $t$ ' are variables for respectively the moments of time and the bearers of the description Moving. 'Moving $(t, x)$ ' can be naturally read as ' $x$ is moving at $t^{\prime}$. ${ }^{26}$ Our analysis is, however, quite different. But before presenting our proposal, we should first discuss some preliminaries on how temporality can be dealt with in the framework of CTT.

${ }^{25}$ Hasnawi and Hodges (2017, p. 61) label such propositions as '( $(a-\ell)$ ' which can be considered as an abbreviation for ' $A$-form lāzim' propositions.

26 This formalization is in accordance with what Hodges and Johnston (2017, p. 1061) put forward following Rescher and vander Nat (1974). The conjunct ' $(\exists t)(\exists x)$ Moving $(t, x)$ ' is added to guarantee the existential import of the proposition. 


\subsection{Preliminaries on Temporal Reference in CTT}

\subsubsection{Time Scales}

Usually when we are talking about time, we are talking about a specific time scale. Depending on the length of the temporal units, we can introduce different time scales. For instance, we can talk about either years, or months, or days, or hours, etc. These time scales can be represented as, respectively, Year, Month, Day, etc. ${ }^{27}$ Each of these time scales is a temporal category. The time scale we are talking about naturally depends on the context in which the proposition is stated. For example, when someone is talking about waking up early in the morning, the time scale such a person considers is probably Day. But when the president of a university is presenting statistics about their graduates, her/his time scale is likely to be Year. In general, we can represent the time scale we are talking about as $T$.

\subsubsection{Time Spans}

An advantage of the CTT-framework as implemented for time reference is that it provides the opportunity of considering not only moments of time, but also time spans and intervals with a beginning and an end. This is particularly important because actions like moving, running, etc. do not happen in a moment. Rather they should be considered as extended events which happen in temporal intervals. Indeed, one of the main shortcomings of the aforementioned analysis of (16) is that it does not consider moving and changing as extended events. So it is important to have tools to express the occurrence of events not only in singular moments of time but also in temporal intervals. This helps us to formally describe how an object that bears a specific description in a specific span of time can also bear some other descriptions in some specific sub-spans of the former span. It is also possible to also express how an object can have the same description with different qualifications in different spans of time. For example, an object that is moving in a span of time might be slow-moving in some parts (or sub-spans) of that span and fast-moving in some others. So it seems to be crucial to see how a span of time can be defined in the framework of CTT.

The category of the spans of a time scale $T$ can be defined as the Cartesian product of $T$ and the set of natural numbers $N .{ }^{28}$ More precisely:

$$
\operatorname{span}(T)=T \times N
$$

To make it clearer, a span of the time scale $T$ is a pair whose first element refers to the beginning point of that span in $T$ and whose second element refers to the number of

\footnotetext{
${ }^{27}$ For a detailed technical definition of time scales, see Ranta (1994, sec. 5.1).
}

${ }^{28}$ For a detailed technical definition of time spans, see Ranta (1994, p. 115). 
temporal units (of the scale $T$ ) which must be added to the beginning point to form the span under discussion. Stated differently, the second element determines the length of the span. So if $d=\left\langle t_{0}, n>: \operatorname{span}(T), d\right.$ is a span of the time scale $T$ which begins at $t_{0}$ and ends at $t_{0}+n$. The span $d$ can also be represented as $\left[t_{0}, t_{0}+n\right]: \operatorname{span}(T)$. As we will shortly see, the following functions are also useful:

$$
\begin{aligned}
& \operatorname{left}(d)=\operatorname{begin}(d)=t_{0}: T \\
& \operatorname{end}(\mathrm{d})=t_{0}+n: T \\
& \operatorname{right}(d)=\operatorname{length}(d)=n: N
\end{aligned}
$$

As an example of the spans of time in the time scale Day, consider the following span:

$<14$ June $2018,31>$ : $\operatorname{span}($ Day)

This span of time begins on 14 July 2018 and extends for 31 days. This is exactly the interval in which Football World Cup 2018 took place.

It is noteworthy that since 0 is a member of $N$, every singular moment of the time scale $T$ can be considered as a span of the length 0 . In other word, every $t$ of the time scale $T$ corresponds to $<t, 0>$ which is a member of $\operatorname{span}(T)$. This shows that everything expressible by the terminology of singular moments of time is also expressible by the terminology of time spans, though the other way around does not hold.

\subsubsection{Saturation vs. Enrichment}

There are at least two different approaches for dealing with temporal reference in the CTT-framework. ${ }^{29}$ More clearly, a proposition which expresses the occurrence of an event (or fact) in a span of time can be seen in at least two different ways. Such a proposition can be seen either as an incomplete propositional function that can be saturated by that specific span of time or as an event (or a fact) that can be timed by a timing function. These two formal terminologies are translatable into each other. This means that everything expressible by one of these two approaches is also expressible by the other. Nonetheless, there is a significant philosophical difference between these two approaches. In the first approach time is primitive. Temporal entities (i.e., singular moments of times or time spans) are independent entities which can be put as the arguments of propositional functions. So, ontologically speaking, complete propositions in some sense depend on these temporal entities. By contrast, in the second approach, events (or facts, or truth-makers of the propositions which express those events) are primitive individuals which can be put as the arguments of the timing functions. Thus, in a sense, time

${ }^{29}$ See Ranta (1994, sec. 5.4). 
is dependent on events. Inspired by François Recanati's terminology, we call these two approaches, respectively, 'saturation' and 'enrichment'. ${ }^{30}$

According to the saturation approach, ' $A$ occurs at the span $d$ of the time scale $T$ ' can be formalized as a propositional function $A$ that is saturated by $d$. So:

$$
A(d): \operatorname{prop}(d: \operatorname{span}(T))
$$

By contrast, according to the enrichment approach $A$ itself is a fully saturated proposition which is made true by different events (or facts) at different time spans. Equivalently, it has different truth-makers or proofs at different time spans. These truth-makers can be timed by a timing function. Informally speaking, the timing function operates upon the set of truth-makers (or justifications, or proofs) of $A$ and determines the time span in which such a truth-maker is obtained. ${ }^{31}$ So if $x$ is a truth-maker of the proposition $A$ (i.e., if $x$ is an event or fact whose occurrence makes $A$ true), then the timing function $\tau$ would determine the span of time in which $x$ is obtained. So the role of $\tau$ can be defined as follows: ${ }^{32}$

$$
\begin{aligned}
& A: \operatorname{prop} \\
& \tau(x): \operatorname{span}(T)(x: A)
\end{aligned}
$$

For example, that a human $x$ is running in the time span $d$ can be expressed by the saturation approach as follows:

$$
\text { Running }(x, d) \text { : prop ( } x \text { :Human, } d: \operatorname{span}(T))
$$

Quite differently, the same proposition can be formalized by the enrichment approach as follows:

$$
\begin{aligned}
& \text { Running }(x): \operatorname{prop}(x: \text { Human }) \\
& \tau(b(x))=d: \operatorname{span}(T)(x: \text { Human, } b(x): \text { Running }(x))^{33}
\end{aligned}
$$

In this formalization $b(x)$ is a truth-maker or evidence for the proposition Running $(x)$; and $\tau$ is a timing function which determines the time span in which $b(x)$ is obtained. So in a sense the time span $d$ is eventually defined by that specific truth-maker of Running $(x)$ that is obtained in that span. In other words, the time span $d$ is given by the operation of the timing function $\tau$ upon the event which makes Running $(x)$ true. Borrowing Aristotelian terminology, we can say that in the enrichment approach time elements are measurements-i.e., timing operations—of (and, consequently, dependent on) events.

\footnotetext{
${ }^{30}$ This terminology is borrowed from Recanati (2007b, 2007a).

${ }^{31}$ Recall that as pointed out before, it is assumed that a proposition has different truth-makers (or proofs or justifications). In the present context this amounts to the assumption that a proposition has different truthmakers during different time spans. That a proposition is true in a specific time span is equivalent to that one of its truth-makers is obtained in that time span.

${ }^{32}$ See Ranta (1994, p. 108).

${ }^{33}$ In order to avoid notational complexity we omitted one variable within the timing function. Indeed, strictly speaking, the correct formalization must be $\tau(x, b(x))=d: \operatorname{span}(T)(x: \operatorname{Human}, b(x): \operatorname{Running}(x))$.
} 
After explaining these preliminary points, we are now well equipped to analyse the temporal interpretation of descriptional propositions through both the saturation and the enrichment approaches.

\subsection{Descriptional Propositions Relativized by Saturation}

Reconsider the proposition (15):

(15) Every moving is changing all the time it is moving.

As we mentioned, moving and changing are extended events which happen in time spans, rather than in singular moments of time. So it is plausible to restate (15) in the language of time spans. If we do so, the result would be something like the following:

(17) Every moving is changing in all the spans in which it is moving.

If we suppose again that the bearers of the description Moving are of the type $O$ and that our time scale is $T$, then our proposal for the logical analysis of (17), in the saturation approach, goes as follows:

(17-CTT-S) $\{\forall z:(\exists d: \operatorname{span}(T))((\exists x: O)$ Moving $(d, x))\}$ Changing $(\operatorname{left}(z), \operatorname{left}(\operatorname{right}(z))$

This can be glossed as:

(17-CTT-S*) Every $z$ that is an element of the set of those objects that are moving at some time span $d$ is subject to change at the time span in which it is moving.

More precisely, here $z$ is a variable for those time spans $d$ at which some $x$ of the type $O$ is moving. So $z$ can be considered as a pair of the canonical form $\langle d,\langle x, b(x)>>$. Thus, $\operatorname{left}(z)$ gives the first constituent of $z$ which is some time span $d$ at which the moving thing is moving. The right constituent of $z$ is the pair of the moving object $x$ and the evidence $b(x)$ which shows that $x$ bears the description Moving at $d$. In other words, in the time span $d$, $b(x)$ is the truth-maker of the proposition that ' $x$ is moving'. Hence, while left $(z)$ yields some time span $d$, left $(\operatorname{right}(z))$ provides the object that is moving at that time span. This is the object of which the grammatical predicate Changing is true. To generalize this approach, consider the following proposition:

(18) Every $S$ is $P$ in all the spans in which it is $S$.

If the bearers of $S$ are of the type $D$ and our time scale is $T$, then the logical analysis of (18) in the language of CTT and based on the saturation approach goes as follows:

(18-CTT-S) $\{\forall z:(\exists d: \operatorname{span}(T))((\exists x: D) S(d, x))\} P(\operatorname{left}(z), \operatorname{left}(\operatorname{right}(z)))$

As we previously mentioned, objects that have a description in a specific span can be described as having other properties in some specific sub-spans of the former span. Now we are well equipped to formalize some of the propositions which express such situations. Consider the following example: 
(19) Everyone who studies mathematics as an undergraduate spends the first year studying calculus.

To formalize this proposition we can take our time scale to be Year. We can also take 'Math $(d, x)$ ' to represent that $x$ studies mathematics as an undergraduate in the span $d$ (where $d: \operatorname{span}(Y e a r)$ and $x:$ Human). More precisely, we assume that $x$ starts studying mathematics at begin $(d)$ and graduates at $e n d(d)$. If so, the first year of $d$ can be referred to by the following function:

$$
\text { first-year }(d)=<\operatorname{begin}(d), 1>\text { : } \operatorname{span}(\text { Year })
$$

So first-year $(d)$ refers to the span of time which begins at begin $(d)$ and extends for 1 year. Now if 'Calculus $(d, x)$ ' expresses that $x$ studies calculus in $d$, then the formal interpretation of (19) would be as follows:

$$
\begin{gathered}
\text { (19-CTT-S }) \quad\{\forall z:(\exists d: \operatorname{span}(\text { Year })((\exists x \text { : Human }) \text { Math }(d, x))\} \text { Calculus(first- } \\
\text { year(left }(z)), \text { left(right }(z))
\end{gathered}
$$

Here again $z$ is the pair $\langle d,<x, b(x)>>$ in which $d$ is a span of time scale Year, $x$ is a human, and $b(x)$ is the evidence that $x$ can be described as studying mathematics at the undergraduate level. To generalize this example, suppose that for every time span $d$, the function s-period $(d)$ determines a specific period of $d$. So first-year is an instance of this kind of functions. But s-period(d) can be defined to determine, for example, the first quarter, the second third, or any other specific part of $d$. Now consider a proposition of the following general form:

(20) Every $S$ is $P$ in a s-period of the time span in which it is $S$.

This can be formalized as follows:

(20-CTT-S) $\{\forall z:(\exists d: \operatorname{span}(T)((\exists x: D) S(d, x))\} P(s-p e r i o d(l e f t(z)), \operatorname{left}(\operatorname{right}(z))$

Developing this approach would help us to formalize some other types of temporal propositions which play a crucial role in the temporal logic of Ibn Sinnā. (21) is one such proposition:

(21) Every (sometime-) $S$ is $P$ sometime while it is $S .{ }^{34}$

The proposition has been usually formalized as follows:

$$
(21-\mathrm{CL})(\forall x)[(\exists t) S(t, x) \supset(\exists \mathrm{t})(S(t, x) \wedge P(t, x))] \wedge(\exists t)(\exists x) S(t, x)^{35}
$$

To analyse (21) using the saturation approach of CTT, we need to add a time span quantifier on the predicate side. Accordingly, (21) can be formalized as:

\footnotetext{
${ }^{34}$ Hasnawi and Hodges (2017, p. 61) label such propositions as ' $(a-m)$ ', which can be considered as an abbreviation for ' $A$-form muwāfiq' propositions.

35 This formalization is suggested by Hodges and Johnston (2017, p. 1061), following Rescher and vander Nat (1974). Again, the conjunct ' $(\exists t)(\exists x) S(t, x)$ ' is added to preserve the existential import.
} 
(21-CTT-S) $\left\{\forall z:(\exists d 1: \operatorname{span}(T)((\exists x: D) S(d 1, x))\}\left(\exists d_{2}: \operatorname{span}(T)\right)\left[S\left(d_{2}, \operatorname{left}(\operatorname{right}(z)) \wedge\right.\right.\right.$ $P\left(d_{2}\right.$, left $\left.(\operatorname{right}(z))\right]$

Here $z$ must still be considered as a pair of the canonical form $<d 1,<x, b(x)>>$. Informally, (21-CTT-S) says that for every object $x$ of the type $D$ that is $S$ in a time span $d 1$, there is a time span $d 2$ in which that object is $P$ while it is $S$. Now we can turn to the enrichment approach.

\subsection{Descriptional Propositions Relativized by Enrichment}

As we previously mentioned, in the enrichment approach time elements are not primitive and have no independent existence. They are dependent on events which make propositions true. In other words, they are dependent objects-i.e., functions. Since this philosophical conception of time is closer to how Ibn Sinā understands this notion, it is more plausible to analyse his temporal propositions based on the enrichment approach (rather than based on the saturation approach in which time elements are primitive and have independent existent). ${ }^{36}$ To see how temporal propositions can be formalized by the enrichment approach, reconsider the proposition (17):

(17) Every moving is changing in all the spans in which it is moving.

In the enrichment approach, this proposition can be formalized as:

(17-CTT-E) $\{\forall z:(\exists x: O)($ Moving $(x)\}$ Changing $(\operatorname{left}(z)) \operatorname{AT}(\tau(\operatorname{right}(z)))$

Here, $z$ is a pair of the canonical form $<x, b(x)>$. So $\operatorname{left}(z)=x$ and $\operatorname{right}(z)=b(x)$. As a result $\tau(\operatorname{right}(z))$ means $\tau(b(x))$. Since $b(x)$ is a truth-maker of ' $x$ is moving', $\tau(b(x))$ gives a time span in which $x$ is moving. Finally AT is an operator that operates upon propositions. Informally speaking, for every span $d$ and every proposition $A, A \operatorname{AT}(d)$ means $\mathrm{A}$ is the case in the time span $d$. So Changing $(\operatorname{left}(z)) \operatorname{AT}(d)$ means $x$ is changing in the time span $d$. Putting together all of these observations, what (17-CTT-E) says is that every $x$ of the type $O$ is changing in all the time spans in which it is moving. In other words, if $x$ is moving in $d$, it would also be changing in this span. To generalize this formalization, reconsider (18):

(18) Every $S$ is $P$ in all the spans in which it is $S$.

If we suppose that the bearer of the description $S$ are of the type $D$, then (18) can be analysed as:

(18-CTT-E) $\{\forall z:(\exists x: D)(S(x)\} P(l e f t(z)) \operatorname{AT}(\tau(\operatorname{right}(z)))$

Finally, reconsider (21):

(21) Every (sometime-) $S$ is $P$ sometime while it is $S$.

\footnotetext{
${ }^{36}$ For Ibn Sīnā time is the number or magnitude of motion. Although he does not explicitly talk about events, his definition of time shows that he does not consider an independent existence for it. This suffices to convince us that the enrichment approach is preferable to the saturation approach. For a detailed discussion on Ibn Sīnā's view regarding time, see Lammer (2018, Chapter 6).
} 
To formalize (21) in the enrichment approach we need to add a temporal quantifier on the side of predicate. In this respect, there is no difference between this approach and the saturation approach. (21) can be formally analysed as:

(21-CTT-E) $\{\forall z:(\exists x: D)(S(x)\}(\exists d: \operatorname{span}(T))[\tau(\operatorname{right}(z))=d \wedge P(\operatorname{left}(z)) \operatorname{AT}(d))]$

Here again $z$ is a pair of the canonical form $<x, b(x)>$ in which $x$ is an object of the type $D$ and $b(x)$ is a witness (or proof) for that $x$ is $S$. So $\tau(\operatorname{right}(z))$ gives a time span in which $x$ is $S$. Accordingly, what (21-CTT-E) says is that for every $x$ of the type $D$ that is $S$, there are some spans $d$ in which $\mathrm{x}$ is both $S$ and and $P$.

\section{$5 \quad$ Existence With and Without Existence Predicate}

According to the ontological system underlying CTT, the fact that a type has been instantiated amounts to showing that the type is not empty. In other words, we should understand the instances of types as witnessing the existence. Therefore, we do not really need to capture the existential import of propositions by adding conjuncts which guarantee the existence of the subject. This can be counted as another advantage of our analysis over some of the earlier studies. ${ }^{37}$ If the import is automatically guaranteed, then a fortiori there is no need to the existence predicate. It is so, at least, unless the existence predicate is defined in some way that allows us to distinguish those instantiations that witness existence from those that do not.

It is worth mentioning that associating the instantiation of a type to the existence of its elements does not prevent us from considering different sorts of existence. Indeed, each instantiation can be understood as representing the kind of existence associated to the type they instantiate. For example, the members of the type $N$ (i.e., natural numbers) do not have the same form of existence as the members of the type Man. Each type has its own form of existence depending upon how the process of its instantiation is defined. Technically speaking, such a process is defined by the rules that introduce the canonical elements of the type under discussion. For example, the notion of existence associated with the set of natural numbers is construction by mathematical induction. By contrast, members of the type Human have a completely different mode of existence. ${ }^{38}$

Having made these points, if someone still insists on adding the existence predicate to the picture, there seems to be no technical difficulty in the way of fulfilling this desire. To give examples we can reconsider the logical analysis provided in (18-CTT-S):

(18-CTT-S) $\{\forall z:(\exists d: \operatorname{span}(T))((\exists x: D) S(d, x))\} P($ left $(z)$, left $(\operatorname{right}(z)))$

The existence predicate can be added to the side of subject as follows:

\footnotetext{
37 See notes 22,24 , and 32 .

${ }^{38}$ The existence of the subject matter of non-mathematical propositions can be presented either by 'logical games' or by dialogical verification procedures. See note 13 .
} 
(18-CTT-S* $\{\forall z:(\exists d: \operatorname{span}(T))((\exists x: D) S(d, x) \wedge \operatorname{Exists}(d, x))\} P(\operatorname{left}(z), l e f t(\operatorname{right}(z)))$

If desired, the existence can also be added to the side of the predicate as follows:

$\left(18-C T T-S^{* *}\right)\{\forall z:(\exists d: \operatorname{span}(T))((\exists x: D) S(d, x) \wedge \operatorname{Exists}(d, x))\} P(\operatorname{left}(z), \operatorname{left}(\operatorname{right}(z)))$ $\wedge$ Exists(left(z),left(right(z)))

By following the same approach, the existence predicate can be added to the propositions relativized by enrichment. However, it should be borne in mind that the existence predicate cannot be introduced rigorously unless we clarify exactly how it is formed. For example, we can say that the objects of the category $O$ exist if and only if they are temporally and spatially indexed. ${ }^{39}$ So if the time scale and the category of location are represented by, respectively ' $T$ ' and ' $L$ ', the existence predicate can be defined as follows:

$\operatorname{Exists}(x, y, z): \operatorname{prop}(x: O, y: L, z: T)$.

Obviously, such a definition of this predicate needs to be embedded into the logical structure of the preceding sentences. We will leave the task of modifying the formal structure to the reader.

\section{Conclusion}

In this chapter we provided a new logical analysis of Ibn Sīnā's descriptional propositions in the framework of CTT. Assuming an anaphoric structure for propositions, we showed that the grammatical predicate of a descriptional proposition is true of an anaphoric tail that encodes not only what the object of predication is, but also how it is. By contrast, in the case of a non-descriptional propositions the anaphoric tail only encodes what the object of predication is.

Our analysis has at least three advantages over its rivals. First, it better reflects the grammatical structure of propositions. Second, it is quite flexible for capturing different temporal features of propositions. In particular, it can enable us to formalize not only sentences which talk about singular moments of time, but also sentences which include actions extended in time spans. Third, the existential import of the universal propositions is automatically guaranteed by the instantiation of the types about which those propositions talk. So we do not need to consider an additional conjunct to our translations just to make sure that the existential import is preserved. Nonetheless, as we saw, there is no obstacle in the way of adding the existence predicate either to the side of subject or to that of the predicate.

Our main focus in this chapter was on how some propositions can be formalized in the framework of CTT. We did not touch on how these formal constructions can be put into

\footnotetext{
${ }^{39} \mathrm{An}$ alternative approach is based on the introduction of the notion of ontological dependence. See Rahman and Redmond (2015).
} 
the syllogism. This should be postponed to a future project. Nonetheless, there is an important insight about the theory of the syllogism which can be seen from here. We showed that the anaphoric structure is quite general and is applicable even when the temporal dimensions of propositions are completely put aside. But if we analyse the propositions of a syllogism as such anaphoric structures, then it would be obvious that the subject-term must always contain a descriptional element in relation to the individual of a domain shared by the premises. So, in a sense, it is assumed by the premises that the kind of the involved object in the inference to be drawn is known. This is one of the general insights on the theory of the syllogism which can be acquired from Ibn Sinnā. 


\section{References}

Ahmed, A. Q. (2011). Avicenna's Deliverance: Logic. Karachi: Oxford University Press. Almog, J. (1991). The What and the How. The Journal of Philosophy, 88(5), 225-244.

Almog, J. (1996). The What and the How II : Reals and Mights. Noûs, 30(4), 413-433.

Chatti, S. (2019a). Logical Consequence in Avicenna's Theory. Logica Universalis, 13(1), 101-133.

Chatti, S. (2019b). The Logic of Avicenna Between al-Qiyās and Manțiq al-Mašriqīyyīn. Arabic Sciences and Philosophy, 29(1), 109-131.

El-Rouayheb, K. (2017). Arabic Logic after Avicenna. In C. Dutilh Novaes \& S. Read (Eds.), The Cambridge Companion to Medieval Logic (pp. 67-93). Cambridge: Cambridge University Press.

El-Rouayheb, K. (2019). The Development of Arabic Logic (1200-1800). Basel: Schwabe Verlag.

Hasnawi, A., \& Hodges, W. (2017). Arabic Logic up to Avicenna. In C. Dutilh Novaes \& S. Read (Eds.), The Cambridge Companion to Medieval Logic (pp. 45-66). Cambridge: Cambridge University Press.

Hodges, W., \& Johnston, S. (2017). Medieval Modalities and Modern Methods: Avicenna and Buridan. IFCoLog Journal of Logics and Their Applications, 4(4), 1029-1073.

Ibn Sīnā. (1910). Manțiq al-mašriqìīn. Cairo: al-Maktaba al-salafìya.

Ibn Sīnā. (1964). al-Šifā̄', al-Manțiq, al-Qiyās. (S. Zāyid, Ed.). Cairo: al-Mațba'a al-amīrīya.

Ibn Sīnā. (1983). al-Išärāt wa-l-tanbīhāt bi-Šarh al-Ṭūsī, al-Manțiq [= Remarks and Admonitions: With Commentary by Tusi]. (S. Dunyā, Ed.) (3rd ed.). Cairo: Dār al-ma‘ārif.

Ibn Sīnā. (1984). Remarks and Admonitions, Part One: Logic,.

Ibn Sīnā. (1985). al-Nağāt. (M. T. Danišpažūh, Ed.). Tehran: Entešārāt-e Dānešgāhe Tehrān.

Lagerlund, H. (2009). Avicenna and Țūsī on Modal Logic. History and Philosophy of Logic, $30(3), 227-239$.

Lammer, A. (2018). The Elements of Avicenna's Physics. Berlin: De Gruyter.

Lorenz, K., \& Mittelstrass, J. (1967). On Rational Philosophy of Language: The Programme in Plato's Cratylus Reconsidered. Mind, 76(301), 1-20.

Martin-Löf, P. (1984). Intuitionistic Type Theory. Computation, Proof, Machine. Napoli: Bibliopolis.

Martin-Löf, P. (2014). Truth of Empirical Propositions. Lecture Held at the University of Leiden, (Transcribed by A.Klev).

Rahman, S., McConaughey, Z., Klev, A., \& Clerbout, N. (2018). Immanent Reasoning or Equality in Action: A Plaidoyer for the Play Level. Dordrecht: Springer.

Rahman, S., \& Redmond, J. (2015). A Dialogical Framwerwork for Fictions as Hypothecial Objects. Filosofia Unisinos, 16(1), 2-21. 
Ranta, A. (1994). Type-Theoretical Grammar. Oxford: Clarendon Press.

Recanati, F. (2007a). It Is Raining (Somewhere). Linguistics and Philosophy, 30(1), 123-146.

Recanati, F. (2007b). Perspectival Thought: A Plea for (Moderate) Relativism. Oxford: Oxford University Press.

Rescher, N., \& vander Nat, A. (1974). The Theory of Modal Syllogistic in Medieval Arabic Philosophy. In N. Rescher (Ed.), Studies in Modality (pp. 17-56). Oxford: Blackwell.

Schöck, C. (2008). Name (ism), Derived Name (ism mushtaqq) and Description (wașf) in Arabic Grammar, Muslim Dialectical Theology, and Arabic Logic. In S. Rahman, H. Tahiri, \& T. Street (Eds.), The Unity of Science in the Arabic Tradition (pp. 329-360). Dordrecht: Springer.

Street, T. (2002). An Outline of Avicenna's Syllogistic. Archiv Für Geschichte Der Philosophie, 84(2), 129-160.

Street, T. (2005). Logic. In P. Adamson \& T. R. C. (Eds.), The Cambridge Companion to Arabic Philosophy (pp. 247-265). Cambridge: Cambridge University Press.

Strobino, R., \& Thom, P. (2017). The Logic of Modality. In C. Dutilh Novaes \& S. Read (Eds.), The Cambridge Companion to Medieval Logic (pp. 342-369). Cambridge: Cambridge University Press.

Sundholm, G. (1989). Constructive Generalized Quantifiers. Synthese, 79(1), 1-12. 